\title{
EL TRIBUNAL DE JUSTICIA DE LA UNIÓN EUROPEA COMO GARANTE DE DERECHOS CONSTITUCIONALES EN LOS ESTADOS: LA DOCTRINA TARICCO
}

ENRIQUE DE MIGUEL CANUTO 
SUMARIO

I. JUICIOS CONSECUTIVOS. II. CASO IVO TARICCO: PRINCIPIO DE PRIMACÍA. 1. Conformidad con el Derecho de la Unión. 2. Consecuencias de la incompatibilidad. 3. Derechos fundamentales. III. CASO M.A.S. Y M.B.: DERECHOS CONSTITUCIONALES. 1. Puntos preliminares. 2. Doctrina jurisprudencial 3. Principio de legalidad penal 4. Competencia compartida. IV. REFLEXIONES CONCLUSIVAS. BIBLIOGRAFÍA. 


\title{
EL TRIBUNAL DE JUSTICIA DE LA UNIÓN EUROPEA COMO GARANTE DE DERECHOS CONSTITUCIONALES EN LOS ESTADOS: LA DOCTRINA TARICCO
}

\author{
ENRIQUE DE MIGUEL CANUTO'1. \\ Catedrático de Derecho financiero. Universidad de Valencia.
}

\section{JUICIOS CONSECUTIVOS}

En el contexto del ordenamiento europeo, la relación entre normas nacionales y normas europeas en las esferas de competencia de la Unión la define el Derecho de la Unión Europea. La escasez de normas sobre el incumplimiento por los particulares del Derecho de la Unión pone en primer plano la pregunta acerca de qué papel pueden jugar, en relación al Derecho de la UE, los principios penales recogidos en las Constituciones de los Estados miembros.

En el caso Taricco, en el campo de la prescripción en materia de IVA, el Tribunal de Justicia de la Unión Europea (TJUE) puso en juego el principio de primacía, entendiendo que el juez nacional debía inaplicar las normas sobre interrupción de la prescripción, en caso de que su aplicación suponga que «un número considerable de asuntos» quedaran impunes y caso de que se vulnere el principio de igualdad de trato entre sanciones protectoras de los intereses de la Unión y sanciones protectoras de los intereses del Estado.

Después, la puesta en práctica de la doctrina Taricco en los procesos pendientes ante los tribunales penales suscitó en Italia delicados conflictos con las garantías constitucionales en materia penal, que llevaron a la Corte d'appello de Milán y a la Corte di cassazione a elevar sendas cuestiones de inconstitucionalidad ante la Corte costituzio-

Facultad de Derecho, Universidad de Valencia, Avenida de los naranjos s/n, 46022, Valencia. Email: Enrique.de-miguel@uv.es. Este trabajo se realiza en el marco del Proyecto de Investigación de la Consellería de Universidades de la Generalitat Valenciana (AICO/2019/108), «Vivificación de los principios, derechos y garantías tributarios ante los retos de la globalización». 
nale. La Corte costituzionale, en el caso M.A.S. y M.B., elevó, a su vez, estas dudas ante el TJUE, acerca de cómo se compagina la anterior doctrina Taricco con los principios superiores del ordenamiento constitucional, como el principio de legalidad penal, incluyendo el principio de precisión de la ley penal aplicable.

El Tribunal de la Unión abrirá un cierto espacio al juego de los principios relativos a la materia penal recogidos en la Constitución del Estado, en el contexto de un ámbito competencial compartido integrante del Derecho de la Unión².

\section{CASO IVO TARICCO: PRINCIPIO DE PRIMACIA}

El caso Ivo Taricco $^{3}$, resuelto por sentencia del TJUE de 8 de septiembre de 2015, es una cuestión prejudicial elevada por el Tribunal de Cuneo (Italia), en el contexto de un proceso penal por defraudación del IVA, relativo a la entrega de botellas de champán ${ }^{4}$.

En el asunto de que conoció el Tribunal de Cuneo, los imputados se hallaban procesados por haber organizado, durante los ejercicios fiscales de 2005 a 2009, una asociación ilícita para delinquir en materia de IVA. Se les imputo la realización de montajes fraudulentos de tipo «fraude carrusel» ${ }^{5}$ en el IVA, mediante constitución de sociedades instrumentales y emisión de documentos falsos por medio de los cuales adquirieron botellas de champán, sin abonar el IVA. Esta operativa permitió a la sociedad Planet Srl disponer de productos a un precio inferior al de mercado que podía revender a sus clientes, falseando de este modo la competencia en dicho mercado.

2 GUASTAFERRO, B. (2018), «Derubricare i conflitti costituzionali per risolverli: sezionando il caso «Taricco», Quaderni costituzionali 2, pp. 441-461 ; GARCIA VITORIA, I. (2018), «La participación de los Tribunales constitucionales en el Sistema europeo de Derechos Fundamentales (a propósito del diálogo entre la Corte Constitucional italiana y el Tribunal de Justicia en el Asunto Taricco)», Revista española de derecho europeo, 67, pp. 139-164; PERLO, N. (2017), «L'affaire Taricco: la voie italienne pour préserver la collaboration des juges dans l'Union européenne», Revue trimestrielle de droit europeen, 4 , pp. 739-768; MATIA PORTILLA, F.J. (2016), «Primacía del Derecho de la Unión y derechos constitucionales: en defensa del Tribunal constitucional», Revista Española de Derecho Constitucional 106 , pp. 479-522.

3 Sentencia del TJUE de 8 de septiembre de 2015, caso Ivo Taricco, asunto C-105/14 (Italia).

4 RODRIGUEZ BEREIJO LEON, M. (2016), «La Sentencia del TJUE en el caso «Ivo Taricco y otros» y la aplicación extensiva del principio de efectividad en relación con la persecución del fraude en el IVA», Revista española de derecho europeo 58, pp. 171-198 ; LUPO, E. (2016), «La primauté del diritto dell“UE e l'ordinamento penale nazionale», Diritto penale contemporáneo 1 , pp. 217-227; PULITANO, D. (2016), «La posta in gioco nelle decisione della Corte costituzionale sulla sentenza Taricco», Diritto penale contemporáneo, 1 , pp 228-237.

5 Sobre el «fraude carrusel» en el IVA puede verse SANZ DIAZ-PALACIOS, J.A. (2016), «La lucha contra el «fraude carrusel» del Impuesto al Valor añadido en Italia: Comentario a una Sentencia del Tribunal de Justicia de la Unión Europea» Análisis Tributario 341, pp. 26-31 ; LANOTTE, M. (2019), «L'impunità degli autori delle frodi carosello e le contromisure per la tutela degli interessi finanziari europei», Diritto penale contemporáneo, 6, pp. 189 a 206. 
Planet recibió facturas emitidas por dichas sociedades instrumentales por operaciones inexistentes. Mientras estas sociedades no presentaron la declaración anual de IVA o, cuando sí la presentaron, no realizaron los pagos correspondientes, en cambio, Planet incluyó las facturas emitidas por las sociedades instrumentales en su contabilidad, deduciendo indebidamente el IVA indicado en las mismas y, por consiguiente, presentó declaraciones anuales del IVA fraudulentas.

Según la resolución de remisión, después de haberse producido varias incidencias procesales en el asunto y tras desestimar las numerosas excepciones formuladas por los imputados en el marco de la audiencia previa celebrada ante él, el tribunal remitente hubo de dictar, por un lado, un auto de sobreseimiento respecto de uno de los imputados, pues las infracciones habían prescrito en lo que le concernía, y, por otro lado, un auto de procesamiento en lo que concierne a los demás acusados y señalar la celebración de una audiencia contradictoria.

El Tribunal remitente precisa que, en virtud de los artículos 2 y 8 del DL no. $74 / 2000$, los delitos de que se acusa a los imputados se castigan con pena de hasta seis años de prisión. En cambio, el delito de asociación ilícita, tipificado en el artículo 416 del Código Penal, del que también podrían resultar culpables los imputados, se castiga con una pena de prisión de hasta siete años para los promotores de la asociación y de hasta cinco años para los meros participantes. De manera que, para los promotores de la asociación ilícita, el plazo de prescripción es de siete años y para los demás, es de seis. El último acto que interrumpió el plazo de prescripción fue la providencia de señalamiento de la audiencia previa.

A pesar de la interrupción de la prescripción, en virtud del artículo 160, último párrafo, del Código Penal, en relación con el artículo 161 de dicho Código, el plazo de prescripción no podía prorrogarse más allá de siete años y seis meses o, en el caso de los promotores de la asociación ilícita, más allá de ocho años y nueve meses, a partir de los hechos delictivos. Según el Tribunal remitente, todos los delitos que aún no han prescrito lo harán, a más tardar, el 8 de febrero de 2018, esto es, antes de que pueda dictarse una resolución judicial definitiva en lo que concierne a los imputados. Esto supone que estos últimos, acusados de haber cometido un fraude del IVA por importe de varios millones de euros, podrían acabar gozando de impunidad debido a la expiración del plazo de prescripción.

No obstante, según el Tribunal remitente, era posible prever esta consecuencia debido a la existencia de la norma recogida en el artículo 160, último párrafo, del Código Penal, en relación con el artículo 161, párrafo segundo, de dicho Código, que, al limitar la prolongación del plazo de prescripción, tras la interrupción de la prescripción, a tan sólo una cuarta parte de su duración inicial, supone, en realidad, que en la mayoría de los procedimientos penales no se interrumpa la prescripción.

Según el Tribunal remitente, los procedimientos penales relativos al fraude fiscal, como el que supuestamente cometieron los imputados, implican por regla general investigaciones muy complejas, de manera que el procedimiento requiere mucho tiempo en la fase de instrucción. Afirma que, si se toman en consideración todas las 
instancias, la duración del procedimiento es de tal magnitud que, en Italia, para este tipo de asuntos, la impunidad no es la excepción, sino la regla. Añade que la Administración tributaria italiana suele encontrarse en la imposibilidad de recuperar el importe de los impuestos defraudados mediante este tipo de delitos.

En este contexto, el Tribunal remitente argumenta que las disposiciones controvertidas facilitan indirectamente la competencia desleal por parte de determinados operadores establecidos en Italia frente a las empresas establecidas en otros Estados, por lo que resultan contrarios al artículo 101 TFUE. Añade que estas disposiciones pueden resultar favorables para determinadas empresas, infringiendo así el artículo 107 TFUE, sobre prohibición de ayudas de Estado. Además, considera que las disposiciones crean, de hecho, una exención en el impuesto sobre el valor añadido no prevista en el artículo 158, apartado 2, de la Directiva 2006/112. Por último, sostiene que la impunidad que se otorga a los defraudadores vulnera el principio rector recogido en el artículo 119 TFUE, según el cual los Estados deben velar por la solidez de sus finanzas públicas.

No obstante, el Tribunal remitente entiende que, si se le permitiera dejar sin aplicación las disposiciones nacionales controvertidas, relativas a la prescripción penal, sería posible garantizar la aplicación efectiva del Derecho de la Unión en Italia.

\section{Conformidad con el derecho de la unión}

El Tribunal remitente pregunta si una normativa nacional en materia de prescripción de las infracciones penales que disponía, en el momento en que se produjeron los hechos del litigio principal, que la interrupción de la prescripción en el marco de un proceso penal relativo a delitos en materia de IVA tenía como consecuencia ampliar el plazo de prescripción en tan solo una cuarta parte de su duración inicial, de manera que las personas imputadas podían beneficiarse de impunidad, supone la introducción de un supuesto de exención ${ }^{6}$ del IVA no contemplado en el artículo 158 de la Directiva 2006/112. En el supuesto de que la respuesta a esta cuestión sea afirmativa, el Tribunal remitente plantea si puede dejar sin aplicación estas disposiciones ${ }^{7}$.

El Tribunal de la Unión comienza precisando que si bien la cuestión prejudicial se refiere al artículo 158 de la Directiva 2006/112, de los motivos de la resolución de remisión se desprende claramente que mediante esta cuestión el Tribunal remitente pide que se dilucide si una normativa nacional como la establecida por las disposicio-

${ }^{6}$ La exención supone la ausencia de nacimiento de la obligación tributaria habiéndose realizado el hecho imponible. La posible existencia de fraude en el IVA presupone el nacimiento de la obligación tributaria. Por lo que la obligación tributaria es un presupuesto lógico del posible delito. La posible prescripción de la deuda o la prescripción del delito, que supone la extinción de responsabilidad por la obligación, nada tiene que ver con exenciones impositivas.

Apartado $\mathrm{n}^{\circ} .34$ y ss. de la sentencia del TJUE de 8 de septiembre de 2015, caso Ivo Taricco, asunto C-105/14. 
nes controvertidas supone un obstáculo para la lucha contra el fraude en materia de IVA en el Estado miembro de que se trata, siendo por ello incompatible con la Directiva 2006/112 y, más en general con el Derecho de la Unión.

Debe partirse de que, en materia de IVA, de la Directiva 2006/112 en relación con el artículo 4 TUE, apartado 3, se desprende que los Estados miembros no sólo tienen la obligación general de adoptar todas las medidas legislativas y administrativas necesarias para garantizar que la recaudación íntegra del IVA en sus territorios respectivos, sino que, además, deben luchar contra el fraude (en este sentido, la sentencia caso Åkerberg Fransson, asunto C-617/10, apartado 25).

En consonancia con el artículo 325 TFUE que obliga a los Estados miembros a combatir las actividades ilegales que afecten a los intereses financieros de la Unión mediante medidas disuasorias y efectivas y, en particular, a adoptar para combatir el fraude que afecte a los intereses financieros de la Unión las mismas medidas que para combatir el fraude que afecte a sus propios intereses (véase, la sentencia caso Åkerberg Fransson, asunto C-617/10, apartado 26).

El Tribunal de Justicia de la Unión Europea ha subrayado que, dado que los recursos propios de la Unión incluyen, con arreglo al artículo 2, apartado 1, letra b), de la Decisión 2007/436, los ingresos procedentes de la aplicación de un tipo uniforme a la base armonizada del IVA determinada según la normas de la Unión, existe un vínculo directo entre la percepción de los ingresos procedentes del IVA respetando el Derecho de la Unión aplicable y la puesta a disposición del presupuesto de la Unión de los recursos IVA correspondientes, ya que cualquier omisión que pudiera producirse en la percepción de aquéllos puede causar una reducción de éstos (véase, la sentencia caso Åkerberg Fransson, asunto C-617/10, apartado 26).

En materia sancionadora si bien es cierto que los Estados miembros disponen de libertad de elección de las sanciones aplicables, que pueden ser sanciones administrativas, sanciones penales o una combinación de ambas, para garantizar la percepción de todos los ingresos procedentes del IVA y, de este modo, proteger los intereses financieros de la Unión de conformidad con lo dispuesto en la Directiva 2006/112 y en el artículo 325 TFUE ( en este sentido, la sentencia caso Åkerberg Fransson , asunto C-617/10, apartado 34 ), no es menos cierto que las sanciones penales pueden resultar indispensables para combatir de manera efectiva y disuasoria algunos casos graves de fraude de IVA.

En este sentido, en virtud del artículo 2, apartado 1, del Convenio sobre Protección de los intereses financieros de las Comunidades europeas ( Convenio PIF»), los Estados miembros deberán tomar las medidas necesarias para que a los comportamientos constitutivos de fraude que afecte a los intereses financieros de la Unión, les sean impuestas sanciones penales efectivas, proporcionadas y disuasorias, entre las que figuren, al menos en caso de fraude grave, penas de privación de libertad.

El concepto de «fraude» se define en el artículo 1 del «Convenio PIF» como «cualquier acción u omisión intencionada relativa [...] a la utilización o a la presentación de declaraciones o de documentos falsos, inexactos o incompletos, que tengan por efecto la disminución ilegal de los recursos del presupuesto general de [la Unión] 
o de los presupuestos administrados por [la Unión] o por su cuenta». Por tanto, este concepto engloba los ingresos procedentes de la aplicación de un tipo uniforme a la base armonizada del IVA determinada según las normas de la Unión. Esta conclusión no queda desvirtuada por que el IVA no sea percibido directamente por cuenta de la Unión, ya que el artículo 1 del Convenio PIF no establece tal requisito, que sería contrario al objetivo de dicho Convenio de luchar con la mayor firmeza posible contra el fraude que afecte a los intereses financieros de la Unión.

En el caso de autos, de la resolución de remisión se desprende que la normativa nacional establece sanciones penales para los delitos enjuiciados en el proceso principal, a saber, la constitución de una asociación ilícita para delinquir en materia de IVA y la comisión de un fraude en este mismo ámbito por una cuantía de varios millones de euros. Cabe apreciar que tales delitos constituyen casos de fraude grave que afectan a los intereses financieros de la Unión.

De las consideraciones expuestas en la presente sentencia se desprende que los Estados miembros deben velar por que tales casos de fraude grave sean castigados mediante sanciones penales efectivas y disuasorias. Además, las medidas adoptadas deben ser las mismas que las adoptadas por los Estados miembros para combatir los casos de fraude con el mismo grado de gravedad que afecten a sus propios intereses financieros.

Es de la incumbencia del órgano jurisdiccional nacional verificar, teniendo en cuenta todas las circunstancias de hecho y de Derecho relevantes, si las disposiciones nacionales aplicables permiten sancionar, de manera efectiva y disuasoria, los casos de fraude grave que afecten a los intereses financieros de la Unión.

Ha de señalarse que ni el órgano jurisdiccional remitente ni los interesados que presentaron alegaciones ante el Tribunal de la Unión han cuestionado el carácter disuasorio en sí mismo de las sanciones penales mencionadas por el propio Tribunal remitente, a saber, una pena que puede alcanzar los siete años de prisión, ni tampoco ha puesto en tela de juicio la conformidad con el Derecho de la Unión del establecimiento en Derecho penal italiano de un plazo de prescripción para hechos constitutivos de fraude que afecten a los intereses financieros de la Unión.

No obstante, de la resolución de remisión se desprende que, habida cuenta de la complejidad y de la duración de los procedimientos penales que concluyen con la adopción de una resolución judicial definitiva, las disposiciones controvertidas, que introducen, en caso de interrupción de la prescripción por alguna de las causas mencionadas en el artículo 160 del Código Penal, una norma en virtud de la cual el plazo de prescripción no puede ampliarse en ningún caso más allá de la cuarta parte de su duración inicial, tiene como consecuencia empírica la neutralización del efecto temporal de la causa de interrupción de la prescripción.

Podría declararse que las medidas establecidas por el Derecho nacional para combatir el fraude y las actividades ilícitas que afectan a los intereses financieros de la Unión no son ni efectivas ni disuasorias, lo que sería incompatible con el artículo 325 TFUE con el Convenio PIF y con la Directiva 2006/112, en relación con el artículo 
4 TUE, apartado 3, si el juez nacional llega a la conclusión de que la aplicación de las disposiciones nacionales en materia de interrupción de la prescripción tiene como consecuencia que, en un número considerable de casos, hechos constitutivos de fraude grave queden impunes desde el punto de vista penal debido a que, por regla general, tales hechos habrán prescrito antes de que la sanción penal prevista por la ley pueda imponerse mediante una resolución judicial definitiva.

Para D. PULITANO, esta declaración supone encomendar al juez penal efectuar una apreciación acerca de la adecuación funcional de la norma sobre prescripción a los fines de prevención del delito, de evitar el resultado de impunidad, lo que envuelve una valoración de política legislativa propia del legislador ${ }^{8}$ y enteramente ajena a la competencia del juez penal ${ }^{9}$.

Además, incumbirá al órgano jurisdiccional remitente verificar si las disposiciones nacionales controvertidas sobre prescripción penal se aplican a los casos de fraude en materia de IVA del mismo modo que a los casos de fraude que afectan únicamente a los intereses financieros de la República Italiana, como exige el artículo 325 TFUE, apartado $2^{10}$.

No sucedería así si el artículo 161, párrafo segundo, del Código Penal estableciera plazos de prescripción más largos para hechos de naturaleza y gravedad comparables, que afectasen a los intereses financieros de Italia. Pues bien, tal y como observó la Comisión en la vista celebrada ante el Tribunal de la Unión, y sin perjuicio de que el tribunal nacional compruebe este extremo, el Derecho italiano no establece ningún plazo de prescripción absoluto en lo que concierne al delito de asociación para delinquir en materia de impuestos especiales sobre las labores del tabaco.

8 PULITANO, D. (2016), «La posta in gioco nelle decisione della Corte costituzionale sulla sentenza Taricco», Diritto penale contemporáneo 1, pp 228-237.

9 En el mismo sentido, después lo veremos, como final de trayecto, la Corte costituzionale, en sentencia $n^{\circ} 115$ de 4 de abril de 2018, concluirá que «la «regola Taricco», per la porzione che discende dal paragrafo 1 dell'art. 325 TFUE, è irrimediabilmente indeterminata nella definizione del «numero considerevole di casi» in presenza dei quali può operare, perché il giudice penale non dispone di alcun criterio applicativo della legge che gli consenta di trarre da questo enunciato una regola sufficientemente definita. Né a tale giudice può essere attribuito il compito di perseguire un obiettivo di politica criminale svincolandosi dal governo della legge al quale è invece soggetto (art. 101, secondo comma, Cost.) «( parágrafo n $\left.{ }^{\circ} 11\right)$.

10 El Tribunal de la Unión precisará después, en su sentencia 2 de mayo de 2018, caso M. Scialdone, asunto C-574/15, que «cuando dos categorías de infracciones se distinguen por diferentes circunstancias que conciernen tanto a los elementos constitutivos de la infracción como a la mayor o menor facilidad para descubrirla, tales diferencias implican, en particular, que el Estado miembro de que se trate no está obligado a establecer un régimen idéntico para ambas categorías». El Tribunal de Varesse había preguntado si era contrario al Derecho de la Unión, que, en el caso, el umbral penal en materia de IVA fuera más elevado que el umbral penal relativo al impuesto sobre la renta de las personas físicas. Puede verse DE AMICIS , G. (2018), «Le soglie di punibilità previste dalla legislazione in materia di reati tributari sono conformi alla normativa europea», Cassazione penale 9, pp. 3030-3036; FEILHES , L. (2018), «TVA, Italie et sanction pénale : le cocktail dangereux à nouveau désamorcé par la Cour de justice», Revue des affaires europeennes, 2, pp. 353-363. 
Dice E. LUPO que la normativa italiana sobre prescripción relativa al IVA está en oposición con el apartado 2 del artículo 325 de TFUE, sobre tutela equivalente a la nacional, porque en delitos relativos al IVA la disciplina sobre interrupción de la prescripción es mucho más favorable que la del análogo delito de contrabando de tabaco elaborado en el extranjero. «L 'identità di misure prescritta dall'art. 325 paragrafo 2 TFUE è cosí chiaramente violata ${ }^{11}$ da parte dello Stato italiano» ${ }^{12}$.

\section{Consecuencias de la incompatibilidad}

¿Qué consecuencias tendría la incompatibilidad de las disposiciones nacionales con el Derecho de la Unión Europea? ¿Cuál sería el papel del juez penal en el supuesto de que el Tribunal nacional llegue a la conclusión de que las disposiciones nacionales no cumplen la exigencia del Derecho de la Unión relativa al carácter efectivo y disuasorio de las medidas de lucha contra el fraude del IVA? Dicho Tribunal habrá de garantizar la plena eficacia del Derecho de la Unión, dejando sin aplicación si es preciso las disposiciones nacionales y neutralizando así la consecuencia de posible impunidad de las conductas, sin que haya de solicitar o esperar la previa derogación de la norma por el legislador o mediante cualquier otro procedimiento de control constitucional (en este sentido, las sentencias caso Berlusconi, asunto C-387/02, apartado 72, y caso Kücükdeveci, asunto C-555/07, apartado 51) ${ }^{13}$.

Debe subrayarse que son obligaciones impuestas por el Derecho primario de la Unión, a saber, por el artículo 325 TFUE, tanto la obligación que incumbe a los Estados miembros de combatir las actividades ilegales que afecten a los intereses financieros de la Unión mediante medidas disuasorias y efectivas como la obligación de adoptar, para combatir el fraude que afecte a dichos intereses, las mismas medidas que para combatir el fraude que afecte a sus propios intereses financieros.

Estas disposiciones de Derecho primario de la Unión imponen a los Estados miembros una obligación de resultado precisa y no sujeta a condición alguna en cuanto

11 LUPO, E. (2016), «La primauté del diritto dell'UE e l’ordinamento penale nazionale», Diritto penale contemporáneo 1 , pp. 217-227.

12 Sin embargo, en sentido contrario, como final de trayecto, en sentencia $\mathrm{n}^{\circ} 115$ de 10 de abril de 2018, la Corte costituzionale concluirá que «bisogna aggiungere che una sufficiente determinazione non sarebbe rintracciabile neppure nell'enunciato della sentenza Taricco, relativo ai «casi di frode che ledono gli interessi finanziari dello Stato membro interessato», per i quali sono stabiliti «termini di prescrizione più lunghi di quelli previsti per i casi di frode che ledono gli interessi finanziari dell'Unione». Si tratta infatti di un enunciato generico, che, comportando un apprezzamento largamente opinabile, non è tale da soddisfare il principio di determinatezza della legge penale e in particolare da assicurare ai consociati una sua sicura percezione»( parágrafo $\mathrm{n}^{\circ} 13$ ).

13 Apartado $\mathrm{n}^{\circ} .49$ y ss. de la sentencia del TJUE de 8 de septiembre de 2015, caso Ivo Taricco, asunto C-105/14. 
a la aplicación de la norma que contienen, recordada en el anterior apartado de la sentencia ${ }^{14}$.

Por consiguiente, en virtud del principio de primacía ${ }^{15}$ del Derecho de la Unión, las disposiciones del artículo 325 TFUE, apartados 1 y 2, producen el efecto, en sus relaciones con el Derecho interno de los Estados miembros, de hacer inaplicable de pleno derecho, por el propio hecho de su entrada en vigor, cualquier disposición contraria de la legislación nacional existente (en este sentido, en particular, la sentencia caso ANAFE, asunto C-606/10, apartado 73).

\section{Derechos fundamentales}

Como cautela, el Tribunal de la Unión dice que «procede añadir que si el órgano jurisdiccional nacional decide dejar sin aplicación las disposiciones nacionales controvertidas, habrá de velar igualmente por que se respeten los derechos fundamentales de las personas afectadas. En efecto, estas últimas podrían verse imponer sanciones que, con toda probabilidad, habrían evitado si se hubieran aplicado las disposiciones de Derecho nacional» ${ }^{16}$.

La explicación está en que algunos de los interesados que han presentado observaciones ante el Tribunal de la Unión se remitieron al artículo 49 de la Carta de los Derechos Fundamentales de la Unión Europea, que recoge los principios de legalidad y de proporcionalidad de los delitos y las penas, según los cuales nadie podrá ser condenado por una acción o una omisión que, en el momento en que haya sido cometida, no constituya una infracción según el Derecho nacional o el Derecho internacional.

No obstante, sin perjuicio de que el Tribunal nacional verifique este extremo, la inaplicación de las disposiciones nacionales controvertidas sólo tendrá como consecuencia

14 La norma del Tratado constitutivo enuncia la necesidad de que los Estados miembros adopten medidas para la protección de los intereses financieros de la Unión, sin efectuar ninguna precisión acerca de qué conceptos financieros están implicados, qué criterios sustantivos deben guiar tales medidas, ni qué sectores del ordenamiento deben quedar involucrados.

15 Puede verse BIGLINO CAMPOS, P. (2007), «La primacía del Derecho comunitario: la perspectiva española», Revista General de Derecho constitucional 3 , pp. 2-25; GROPPI, T. (2006), «La primauté del Derecho europeo sobre el Derecho constitucional nacional: un punto de vista comparado», Revista de Derecho Constitucional Europeo 5 , pp. 225-244; NETTESHEIM, M. (2003), «El significado constitucional de la primacía del Derecho Comunitario / de la Unión», Revista española de Derecho europeo 6 , pp. 279-289; PUISSOCHET, J.-P. , de MENDIZABAL ALLENDE, R., y CAMPOS SANCHEZBORDONA, M. (2006), «La primacía del Derecho comunitario», Estudios de Derecho judicial 95 , pp. 19-69; RUIZ-JARABO y COLOMER, D., (1986) «La primacía del Derecho comunitario europeo», Noticias de la Unión europea, $\mathrm{n}^{\circ}$. 12, pp. 97-101; SANTAMARIA DACAL, A.I. (2009), «Una reflexión más sobre la primacía del Derecho comunitario con ocasión de la sentencia Michaniki y a la luz del Tratado de Lisboa», Revista española de Derecho europeo, 30, pp.223-241.

${ }_{16}$ Apartado $\mathrm{n}^{\circ} .53$ y ss. de la sentencia del TJUE de 8 de septiembre de 2015, caso Ivo Taricco, asunto C-105/14. 
impedir que se acorte el plazo de prescripción general en el marco de un procedimiento penal pendiente, permitir un enjuiciamiento efectivo de los hechos imputados y garantizar, en su caso, la igualdad de trato entre las sanciones que tienen como finalidad proteger, respectivamente, los intereses financieros de la Unión y los de Italia. Tal inaplicación del Derecho nacional no vulnera los derechos de los imputados garantizados por el artículo 49 de la Carta.

En efecto, en modo alguno resultaría de dicha inaplicación la condena de los imputados por una acción u omisión que en el momento de su comisión no constituyese una infracción sancionada penalmente por el Derecho nacional (véase, por analogía, la sentencia caso Niselli, asunto C-457/02, apartado 30), ni la aplicación de una sanción que, en ese momento, no estuviera prevista por dicho Derecho. Al contrario, los hechos que se recriminan a los imputados en el procedimiento principal, en el momento en que se cometieron, eran constitutivos de la misma infracción y se castigaban con las mismas penas que las actualmente previstas.

Corrobora esta conclusión la jurisprudencia del Tribunal Europeo de Derechos Humanos relativa al artículo 7 del Convenio Europeo de Derechos Humanos, que consagra derechos que se corresponden con los garantizados por el artículo 49 de la Carta. En efecto, según esa jurisprudencia, la prórroga del plazo de prescripción y su aplicación inmediata a los procedimientos en trámite, en su calidad de norma de procedimiento, no constituyen una vulneración de los derechos garantizados por el artículo 7 del Convenio ${ }^{17}$, pues no puede considerarse que esta disposición impida la ampliación de los plazos de prescripción cuando los hechos imputados no han prescrito $^{18}$.

Debe concluirse que una normativa nacional sobre la prescripción de las infracciones penales que, en el momento en que se produjeron los hechos del litigio principal, disponía que la interrupción de la prescripción en el marco de un proceso penal relativo a fraudes graves en materia de IVA tenía como consecuencia ampliar el plazo de prescripción en tan solo una cuarta parte de su duración inicial, puede ser contraria a las obligaciones que el artículo 325 TFUE, impone a los Estados, si dicha normativa impide imponer sanciones efectivas y disuasorias en un número considerable de casos de fraude grave que afecten a los intereses financieros de la Unión, o establece en el caso de fraudes que afecten a los intereses financieros del Estado plazos de prescripción más largos que en el caso de fraudes que afecten a los intereses financieros de la Unión, extremo que corresponde verificar al órgano jurisdiccional nacional. Incumbe a éste garantizar la plena eficacia del artículo 325 TFUE, dejando si es preciso sin aplicación las

17 En el contexto argumental en que es introducido este argumento incurre en petición de principio o circulus in demostrando, porque si el delito prescribe o no en el caso es precisamente el objeto del debate.

18 En este sentido, las sentencias del TEDH Coëme contra Bélgica, nº 32492/96 § 149 ; Scoppola contra Italia ( $\left.\mathrm{n}^{\circ} 2\right), \mathrm{n}^{\circ} 10249 / 03, \S 110,17$ de septiembre de 2009 , y OAO Neftyanaya Kompaniya Yukos contra Rusia, n 14902/04, $\S \S 563,564$ y 570, 20 de septiembre de 2011. 
disposiciones del Derecho nacional que impidan al Estado dar cumplimiento a las obligaciones que le impone dicho artículo.

Sin embargo, la solución dada a la cuestión prejudicial por el Tribunal de la Unión, potenciando la primacía del Derecho de la Unión, suscitará después dudas de constitucionalidad, en los diferentes escenarios de los litigios pendientes ante los tribunales ordinarios italianos, a la hora de aplicar tal doctrina, por parte de la Corte d'appello de Milán y a la Corte di cassazione, que elevarán, por ello, cuestiones de constitucionalidad ante la Corte costituzionale.

\section{CASO M.A.S. Y M.B.: DERECHOS CONSTITUCIONALES}

El caso M.A.S. y M.B. ${ }^{19}$, resuelto por sentencia del Tribunal de la Unión de 5 de diciembre de 2017, es una cuestión prejudicial elevada la Corte costituzionale italiana, en el marco de sendas cuestiones de inconstitucionalidad planteadas por la Corte d'appello de Milán y la Corte de cassazione, en relación con la primacía de la norma europea fallada en la sentencia del anterior caso Taricco ${ }^{20}$.

En la sentencia Taricco, el Tribunal de la Unión había declarado que el artículo 160, último párrafo, en relación con el artículo 161 del Código penal, en la medida en que prevén que la interrupción de la prescripción en el marco de un proceso penal relativo a fraudes graves en materia de IVA tiene como consecuencia ampliar el plazo de prescripción en tan sólo una cuarta parte de su duración inicial, podían ser contrarios a las obligaciones que el artículo 325 TFUE impone a los Estados, en el caso de que las disposiciones impidan imponer sanciones efectivas y disuasorias en un número considerable de casos de fraude grave que afecten a los intereses financieros de la Unión o en el caso de que establezcan ante fraudes que afecten a los intereses financieros del Estado plazos de prescripción más largos que en el caso de fraudes que afecten a los intereses financieros de la Unión. El Tribunal de la Unión declaró también que corresponde al Tribunal nacional competente garantizar la plena eficacia del artículo 325 TFUE, dejando si es preciso sin aplicación la norma nacional que impida al Estado responsable dar cumplimiento a sus obligaciones supranacionales.

19 Sentencia del TJUE de 5 de diciembre de 2017, caso M.A.S. y M.B., asunto C-42/17, ( Italia)

20 Puede verse FACCHINETTI, A. (2018), «La protección de los derechos humanos en la Unión Europea mediante el diálogo judicial: comentario a la sentencia del TJUE en el asunto Taricco II», Revista General de Derecho Europeo 45, pp. 252-275 ; FAGGIANI, V. (2018), «El diálogo jurisdiccional tras la sentencia del TJUE M.A.S. y M.B.: entre estándar europeo de protección y tendencias centrípetas», Revista de Derecho Comunitario Europeo 60, pp. 639-676 ; VIGANO, F. (2017), «Legalità 'nazionale' e legalità 'europea' in materia penale: I difficili equilibrismi della Corte di giustizia nella sentenza M.A.S. («Taricco II»)», Rivista italiana di Diritto e Procedura penale, 4, pp. 1281-1314; VITALE, G. (2018), «L'attesa sentenza «Taricco bis»: brevi riflessioni», European papers: a journal on law and integration, 1, pp. 445-458; MORI, P. (2017), «La Corte constituzionale chiede alla Corte di giustizia di rivedere la sentenza Taricco: difesa dei controlimiti o rifiuto delle limitazioni di sovranità in materia penale?», Rivista di diritto internazionale, 2, pp. 407-446. 
La Corte suprema di cassazione y la Corte d'appello di Milano plantearon cuestiones de constitucionalidad ante la Corte costituzionale, considerando que la doctrina establecida en la sentencia del caso Taricco es aplicable en el marco de los dos procesos penales pendientes ante ellos ${ }^{21}$. En efecto, los mencionados procedimientos se refieren a infracciones tipificadas en el Decreto n. ${ }^{\circ}$ 74/2000 que pueden calificarse de graves. Además, según los mencionados tribunales, tales infracciones habrían prescrito si fuesen aplicables las disposiciones controvertidas del Código Penal, mientras que, de no aplicarse, dichos procedimientos podrían desembocar en una sentencia de condena.

Además, la Corte d'appello di Milano ${ }^{22}$ duda de que se respete la obligación que se desprende del artículo 325 TFUE, apartado 2, sobre igualdad de trato entre sanciones, en lo que se refiere al procedimiento penal pendiente ante ella. En efecto, el delito de asociación de malhechores para el contrabando de labores de tabaco extranjeras, previsto en el artículo 291 quater del Decreto del Presidente della Repubblica n. 43, testo unico delle disposizioni legislative in materia doganale, de 23 de enero de $1973^{23}$, si bien es asimilable a las infracciones comprendidas en el Decreto n. ${ }^{\circ} 74 / 2000$, como las controvertidas en los procedimientos principales, tal delito no está sometido a las mismas reglas sobre límites máximos del plazo de prescripción que estas infracciones.

Así, la Corte suprema di cassazione y la Corte d'appello di Milano consideran que, conforme a la doctrina establecida en la sentencia caso Taricco, en los procesos pendientes, deberían abstenerse de aplicar el plazo de prescripción previsto en las disposiciones controvertidas del Código Penal y entrar a resolver sobre el fondo del asunto, lo que podría colisionar con garantías constitucionales.

La Corte costituzionale expresa sus dudas sobre la compatibilidad de la solución europea con los principios superiores del ordenamiento constitucional italiano y con el respeto de los derechos inalienables de la persona. Dicha solución, en los procesos pendientes, podría menoscabar el principio de legalidad de los delitos y las penas, que exige que las disposiciones penales se determinen con precisión y prohíbe que sean retroactivas.

La Corte costituzionale parte de que, en el ordenamiento jurídico italiano, el régimen de la prescripción en materia penal tiene carácter material y, por tanto, está

21 Nada tiene que ver este escenario con el caso A y B, asunto C-112/13, cuestión prejudicial elevada por el Oberster Gerichtshof de Austria , resuelto por sentencia del Tribunal de la Unión de 11 de septiembre de 2.014, sobre conformidad con el Derecho de la Unión de que los tribunales ordinarios que conocen del fondo del asunto, en caso de una norma que vulnere la Carta de derechos fundamentales deban solicitar la anulación de la norma interna ante el Tribunal constitucional (Verfassungsgerichtshof), sin poder limitarse a su inaplicación en el proceso por razón de primacía.

22 LUPO precisa que en el proceso ante el Tribunal de apelación de Milán en que fue elevada cuestión de inconstitucionalidad, el delito es cometido con anterioridad a la sentencia del caso Taricco y el acto interruptivo de la prescripción también se produjo antes de la sentencia (tempus regit actum), aunque sus efectos perduraron hasta después de la sentencia. Por lo que, para este autor, aplicar la doctrina Taricco supondría atribuir eficacia retroactiva a la sentencia europea (LUPO, E., (2016) «La primauté del diritto dell'UE e l'ordinamento penale nazionale», Diritto penale contemporáneo 1, pp. 217-227).

23 GURI n. ${ }^{\circ} 80$, de 28 de marzo de 1973. 
comprendido en el ámbito de aplicación del principio de legalidad, previsto en el artículo 25 de la Constitución italiana. Es por ello por lo que dicho régimen debería estar establecido en reglas precisas que estuvieran vigentes en el momento de la comisión de la infracción de que se trate.

En estas circunstancias, la Corte costituzionale considera que está llamada, por los órganos jurisdiccionales afectados, a pronunciarse acerca de si la doctrina enunciada en la sentencia caso Taricco respeta la exigencia de determinación normativa que, según la Constitución italiana, debe caracterizar la normativa penal material.

Para ello, según dicho Tribunal, se debe, en primer lugar, verificar si la persona afectada podía saber, en el momento de la comisión de la infracción de que se trata, que el Derecho de la Unión impone al juez nacional, cuando se den las circunstancias establecidas en la sentencia del caso Taricco, la no aplicación de las disposiciones debatidas del Código Penal.

El Tribunal remitente recuerda que la exigencia relativa a que el carácter penal de la infracción y la pena aplicable puedan ser determinables previa y claramente por el autor del comportamiento punible resulta también de la jurisprudencia del Tribunal Europeo de Derechos Humanos relativa al artículo 7 del Convenio Europeo de Derechos Humanos.

En segundo lugar, el Tribunal remitente señala que la dificultad de que sentencia caso Taricco no precisa suficientemente los elementos que el juez nacional debe tomar en consideración para determinar el «número considerable de casos» a los que se vincula la aplicación de la doctrina resultante de esa sentencia, cometido que exigiría al juez penal una actuación discrecional sin regla alguna limitadora en tal extremo.

Por otra parte, según este Tribunal, la sentencia caso Taricco no se pronuncia sobre la compatibilidad de la doctrina que establece con los principios supremos del orden constitucional italiano y confió expresamente esta tarea a los jueces nacionales competentes. El Tribunal remitente destaca, que, en el emblemático apartado 53 de la sentencia, se señala que si el Tribunal nacional decide dejar sin aplicación las disposiciones del Código Penal controvertidas, habrá de velar igualmente por que se respeten los derechos fundamentales de las personas afectadas. El tribunal remitente añade que, después, en el apartado 55 de la misma sentencia, se reitera que la referida inaplicación por razón de primacía es argumentada sin perjuicio de que el Tribunal nacional verifique el respeto de los derechos de los acusados.

Además, el Tribunal remitente enfatiza que, en la sentencia del caso Taricco, el Tribunal de la Unión se había pronunciado sobre la compatibilidad de la doctrina establecida en esta sentencia con el artículo 49 de la Carta de los Derechos Fundamentales de la Unión Europea solamente en lo que refiere al principio de irretroactividad. La Corte costituzionale tiene la destreza de visibilizar que, sin embargo, el Tribunal de la Unión entonces no examinó el otro aspecto o dimensión del principio de legalidad de los delitos y las penas, a saber, la exigencia de que la normativa relativa al régimen sancionador debe ser suficientemente precisa. 
Según la Corte remitente la exigencia de precisa determinación forma parte de las tradiciones constitucionales comunes a los Estados miembros, que está presente también en el sistema de protección del CEDH, y que, por tanto, corresponde a un principio general ${ }^{24}$ del Derecho de la Unión. Según el Tribunal remitente, si el régimen de prescripción en materia penal en el ordenamiento jurídico italiano fuese considerado de naturaleza procesal y no material, incluso en tal caso debería aplicarse según reglas precisas.

\section{Puntos preliminares}

El Tribunal de la Unión comienza subrayando ${ }^{25}$ que el proceso prejudicial previsto en el artículo 267 TFUE establece un diálogo de juez a juez ${ }^{26}$ entre el Tribunal de Justicia y los órganos jurisdiccionales de los Estados miembros que tiene como finalidad garantizar la unidad de interpretación del Derecho de la Unión, así como su coherencia, su plena eficacia y su autonomía ${ }^{27}$.

El proceso establecido por el artículo 267 TFUE funciona por tanto como un instrumento de cooperación entre el Tribunal de la Unión y los órganos jurisdiccionales nacionales, por medio del cual el primero aporta a los segundos los elementos de interpretación del Derecho de la Unión que precisan para la solución del litigio que deban dirimir ( en este sentido, la sentencia de 5 de julio de 2016, caso Ognyanov, asunto C-614/14, apartado 16).

Cuando se pronuncia sobre cuestiones prejudiciales, en el marco del reparto de competencias entre los Tribunales de la Unión y los nacionales, el Tribunal de la Unión debe tener en cuenta el contexto fáctico y normativo en el que se insertan las cuestiones prejudiciales, tal como lo define la resolución de remisión (sentencia de 26 de octubre de 2017, caso Argenta Spaarbank, asunto C-39/16, apartado 38).

En el marco del proceso que dio lugar a la sentencia caso Taricco, el Tribunale di Cuneo preguntó respecto a la interpretación de los artículos 101 TFUE, 107 TFUE y 119 TFUE y del artículo 158 de la Directiva 2006/112, relativa al impuesto sobre el valor añadido. Sin embargo, en la sentencia caso Taricco, el Tribunal de la Unión

24 Ahora bien, «puede haber derechos protegidos por el CEDH y derechos fundamentales de las tradiciones constitucionales, que no estén tipificados en la Carta de la Unión. Estos son, entiendo, los que ahora revestirán la condición de «principios generales». Los de la Carta tienen en la actualidad, tras el Tratado de Lisboa, la condición de derechos positivizados o codificados y ya no revisten la condición de principios» (DE MIGUEL CANUTO, E. (2012), «Metodología de la definición y en la protección de los derechos fundamentales de la Unión europea», Tribuna Fiscal 255, pp. 16-27).

25 Apartado $\mathrm{n}^{\circ} .22$ y ss. de la sentencia del TJUE de 5 de diciembre de 2017, caso M.A.S. y M.B., asunto C-42/17.

26 Puede verse TENORIO SANCHEZ, P.J. (2013), «Diálogo entre tribunales y protección de los derechos fundamentales en el ámbito europeo», Revista General de Derecho Europeo, 31.

27 Este sentido, puede verse el Dictamen 2/13 (Adhesión de la Unión al CEDH), de 18 de diciembre de 2014, apartado 176. 
consideró necesario, a efectos del proceso penal pendiente ante el mencionado tribunal italiano, proporcionarle una interpretación del artículo 325 de TFUE.

En el proceso principal, la Corte costituzionale plantea una posible vulneración del principio de legalidad de los delitos y las penas que podría resultar de la obligación, establecida en la sentencia caso Taricco, de no aplicar las disposiciones controvertidas del Código Penal habida cuenta del carácter material de las normas de prescripción previstas en el ordenamiento italiano, que implica que esas reglas sean razonablemente previsibles en el momento de la comisión de las infracciones sin que puedan ser modificadas in peius con carácter retroactivo y, por otra parte, de la exigencia de que toda normativa nacional relativa al régimen de imputación penal debe estar fundamentada en una base legal suficientemente precisa para poder delimitar y orientar la apreciación del juez nacional.

Habida cuenta de los nuevos interrogantes que ha planteado la Corte costituzionale respecto a este principio de legalidad y que no habían sido puestos en su conocimiento en el caso que dio lugar a la sentencia caso Taricco, el Tribunal de la Unión es consciente de que le corresponde precisar la interpretación llevada a cabo por dicha sentencia del artículo 325 TFUE, apartados 1 y 2.

\section{Doctrina jurisprudencial}

El Tribunal de la Unión, como no podía ser de otro modo, comienza evocando su propia doctrina expuesta con anterioridad.

El Tribunal remitente pregunta, si el artículo 325 TFUE obliga al juez nacional a abstenerse de aplicar, en el marco de los procesos penales pendientes sobre infracciones en el ámbito del IVA, disposiciones internas en materia de prescripción que forman parte del Derecho material nacional que impiden la imposición de sanciones penales efectivas y disuasorias en un número considerable de casos de fraude grave que afecten a los intereses financieros de la Unión o que establezcan en el caso de fraudes que afecten a estos intereses plazos de prescripción más cortos que en el caso de fraudes que afecten a los intereses financieros del Estado, incluso si el cumplimiento de esta obligación supone una vulneración del principio de legalidad de los delitos y las penas, debido a la falta de precisión de la ley aplicable o a una aplicación retroactiva de la misma ${ }^{28}$.

El Tribunal de la Unión parte de que el artículo 325 TFUE, apartados 1 y 2, impone a los Estados miembros el deber de combatir las actividades ilegales que afecten a los intereses financieros de la Unión mediante medidas efectivas y disuasorias y la obligación de adoptar para combatir el fraude que afecte a los intereses financieros de la Unión las mismas medidas que para combatir el fraude que afecte a sus propios intereses financieros.

${ }^{28}$ Apartado $^{\circ} 29$ y ss de la sentencia del TJUE de 5 de diciembre de 2017, caso M.A.S. y M.B., asunto C-42/17. 
Dado que, con arreglo a la Decisión 2014/335/UE, Euratom del Consejo, de 26 de mayo de 2014, sobre el sistema de recursos propios de la Unión ${ }^{29}$, los recursos propios de la Unión incluyen los ingresos procedentes de la aplicación de un tipo uniforme a la base armonizada del IVA, existe un vínculo directo entre la percepción de los ingresos del IVA respetando el Derecho de la Unión aplicable y la puesta a disposición del presupuesto de la Unión de los recursos IVA correspondientes, puesto que cualquier omisión que pudiera producirse en la percepción de aquéllos puede causar una reducción de éstos ( en este sentido, las sentencias de 26 de febrero de 2013 , caso Åkerberg Fransson, asunto C-617/10, apartado 26, y caso Taricco, apartado 38).

Corresponde a los Estados garantizar que los recursos propios de la Unión se perciban de forma eficaz (en este sentido, la sentencia de 7 de abril de 2016, caso Degano Trasporti, asunto C-546/14, apartado 21). A este respecto, los Estados deben proceder al cobro de las cantidades correspondientes a los recursos propios que, debido a la existencia de fraudes, hayan sido sustraídas del presupuesto de la Unión.

Para garantizar la percepción íntegra de los ingresos procedentes del IVA y, de este modo, tutelar los intereses financieros de la Unión, los Estados disponen de libertad de elección de las sanciones aplicables, que pueden adoptar la forma de sanciones administrativas, sanciones penales o una combinación de ambas ( en este sentido, las sentencias de 26 de febrero de 2013, caso Åkerberg Fransson, asunto C-617/10, apartado 34, y el anterior caso Taricco, apartado 39).

Debe señalarse, en primer lugar, que las sanciones penales pueden resultar indispensables para combatir de manera efectiva y disuasoria algunos casos graves de fraude de IVA ( en este sentido, la sentencia caso Taricco, apartado 39). Los Estados miembros, para no incumplir las obligaciones que les impone el artículo 325 TFUE, apartado 1, deberán velar por que, en casos de fraude grave que afecte a los intereses financieros de la Unión en materia de IVA, se adopten sanciones penales efectivas y disuasorias.

Se deriva que debe considerarse que los Estados miembros incumplen las obligaciones que les impone el artículo 325 TFUE, apartado 1, cuando las sanciones penales adoptadas para reprimir los fraudes graves en materia de IVA no permiten garantizar de manera eficaz la percepción de la totalidad del impuesto. Por ello, los Estados deben velar también por que las normas de prescripción previstas por el Derecho interno permitan una represión efectiva de las infracciones vinculadas a tales fraudes.

En segundo lugar, con arreglo al artículo 325 TFUE, apartado 2, los Estados miembros, para combatir el fraude que afecte a los intereses financieros de la Unión, en concreto en materia de IVA, deberán adoptar las mismas medidas que para combatir el fraude que afecte a sus propios intereses financieros, conforme al principio de igualdad de trato o «tutela equivalente entre sanciones».

En cuanto a las consecuencias de una posible incompatibilidad de una legislación nacional con el artículo 325 TFUE, apartados 1 y 2, de la jurisprudencia del Tribunal de la Unión se desprende que el mencionado artículo establece obligaciones de resul-

29 DO 2014, L 168, p. 105. 
tado precisas a cargo de los Estados miembros, no sujetas a condición alguna en cuanto a la aplicación de las reglas recogidas en dichas disposiciones.

Corresponde por tanto a los Tribunales nacionales competentes dar plenos efectos a las obligaciones que resultan del artículo 325 TFUE y dejar sin aplicación disposiciones internas, en particular en el ámbito de la prescripción, que, en el marco de un procedimiento relativo a infracciones graves en materia de IVA, impiden la aplicación de sanciones efectivas y disuasorias para luchar contra los fraudes que afecten a los intereses financieros de la Unión.

Cabe recordar que, en el apartado 58 de la sentencia Taricco, se consideró que las disposiciones nacionales controvertidas podían ser contrarias a las obligaciones que el artículo 325 TFUE impone al Estado, en el supuesto de que dichas disposiciones impidan imponer sanciones efectivas y disuasorias en un número considerable de casos de fraude grave que afecten a los intereses financieros de la Unión o en el supuesto de que establezcan para fraudes que afecten a dichos intereses financieros plazos de prescripción más cortos que en el caso de fraudes que afecten a los intereses financieros del Estado miembro de que se trate.

Si bien, desde el punto de vista de la división de poderes, incumbe principalmente al legislador nacional establecer reglas de prescripción que permitan cumplir con las obligaciones que resultan del artículo 325 TFUE, a la luz de las conclusiones alcanzadas por el Tribunal de la Unión en la sentencia del caso Taricco. Corresponde, en efecto, al legislador garantizar que el régimen nacional de prescripción en materia penal no conduzca a la impunidad de un número considerable de casos de fraude grave en materia de IVA o no sea, para las personas acusadas, más severo en casos de fraudes que afecten a los intereses financieros del Estado que en los que afecten a los intereses financieros de la Unión.

Cabe recordar también que la decisión de un legislador nacional de ampliar un plazo de prescripción con aplicación inmediata del nuevo plazo, incluso a hechos imputados que aún no han prescrito, no vulnera, ab initio, el principio de legalidad de los delitos y las penas (en este sentido, la sentencia caso Taricco, apartado 57 y la jurisprudencia del TEDH evocada).

Ahora bien, el Tribunal de Justicia de la Unión, en el caso M.A.S. y M.B., a continuación, profundizara en su reflexión iniciada en el caso Taricco, desde dos premisas. La primera, que la primacía del Derecho de la Unión presupone la competencia de la Unión, y, la segunda, que el principio de legalidad penal forma parte de las tradiciones constitucionales de los Estados miembros.

\section{Principio de legalidad penal}

El Tribunal de Justicia de la Unión, caso M.A.S. y M.B., evoca la importancia que reviste, tanto en el ordenamiento jurídico de la Unión como en los ordenamientos jurídicos nacionales, el principio de legalidad de los delitos y las penas, en sus exi- 
gencias relativas a la previsibilidad, la precisión y la irretroactividad de la Ley penal aplicable ${ }^{30}$.

Este principio, tal y como queda recogido en el artículo 49 de la Carta, se impone a los Estados cuando éstos aplican el Derecho de la Unión, en virtud del artículo 51, apartado 1, de la misma, como es el caso cuando prevén, en el marco de las obligaciones que les impone el artículo 325 TFUE, la imposición de sanciones penales por las infracciones en materia del IVA. Así, la necesidad de garantizar que los recursos de la Unión se perciban de forma eficaz no puede ir en contra del respeto de este principio (véase, por analogía, la sentencia de 29 de marzo de 2012, caso Belvedere Costruzioni, asunto C-500/10, apartado 23).

Además, el principio de legalidad de los delitos y las penas forma parte de las tradiciones constitucionales de los Estados miembros (véanse, en lo tocante al principio de irretroactividad de la ley penal, las sentencias de 13 de noviembre de 1990, caso Fedesa, asunto C-331/88, apartado 42, y de 7 de enero de 2004, caso X, asunto C-60/02, apartado 63) y ha sido recogido por distintos tratados internacionales, en particular en el artículo 7, apartado 1 , del CEDH ( en este sentido, la sentencia de 3 de mayo de 2007, caso Advocaten voor de Wereld, asunto C-303/05, apartado 49).

En la Carta de los Derechos Fundamentales, de sus Explicaciones se desprende que, en virtud del artículo 52, apartado 3, de la Carta, el derecho reconocido en su artículo 49 tiene el mismo sentido y el mismo alcance que el derecho garantizado por el CEDH.

En lo que atañe a los requisitos derivados del principio de legalidad de los delitos y las penas, procede señalar, en primer lugar, que el Tribunal Europeo de Derechos Humanos ha declarado, a propósito del artículo 7, apartado 1 , del CEDH, que, en virtud de este principio, las disposiciones penales deben respetar determinados requisitos de accesibilidad y de previsibilidad tanto en lo que respecta a la definición de la infracción como a la determinación de la pena ${ }^{31}$.

En segundo lugar, el requisito de la precisión de la ley aplicable, que es inherente a este principio, implica que la ley defina de manera clara las infracciones y las penas con las que se castigan. Este requisito se cumple cuando el justiciable puede saber, a partir del texto de la disposición pertinente y, si fuera necesario, con ayuda de la interpretación que de ella hacen los tribunales, qué actos y qué omisiones desencadenan su responsabilidad penal (en este sentido, la sentencia de 28 de marzo de 2017 , caso Rosneft, asunto C-72/15, apartado 162).

30 Apartado $n^{\circ} .51$ y ss. de la sentencia del TJUE de 5 de diciembre de 2017, caso M.A.S. y M.B., asunto C-42/17.

31 Pueden verse TEDH, sentencias de 15 de noviembre de 1996, Cantoni c. Francia, CE:ECHR:1996:1115JUD001786291, § 29; de 7 de febrero de 2002, E.K. c. Turquía, CE:ECHR:2002:0207JUD002849695, § 51; de 29 de marzo de 2006, Achour c. Francia, CE:ECHR:2006:0329JUD006733501, § 41, y de 20 de septiembre de 2011 , OAO Neftyanaya Kompaniya Yukos c. Rusia, CE:ECHR:2011:0920JUD001490204, §§ 567 a 570. 
En tercer lugar, el principio de irretroactividad de la ley penal se opone a que un juez pueda, durante un proceso penal, bien sancionar penalmente un comportamiento que no está prohibido por una norma nacional adoptada antes de la comisión de la infracción imputada, bien agravar el régimen de responsabilidad penal de aquellos comportamientos que sean objeto del proceso (véase, por analogía, la sentencia de 8 de noviembre de 2016, caso Ognyanov, asunto C-554/14, apartados 62 a 64).

Sobre la aplicación al caso, el Tribunal de la Unión asume que en el ordenamiento jurídico italiano, como se ha señalado en la presente sentencia, los requisitos de previsibilidad, de precisión y de irretroactividad inherentes al principio de legalidad de los delitos y las penas se aplican también al régimen de prescripción relativo a las infracciones penales en materia del IVA.

De ello resulta, por una parte, que corresponde al juez nacional verificar si la apreciación exigida por la doctrina de la sentencia del caso Taricco, según la cual las disposiciones controvertidas impiden imponer sanciones efectivas y disuasorias en un número considerable de casos de fraude grave que afectan a los intereses financieros de la Unión, conduce a una situación de incertidumbre en el ordenamiento jurídico italiano, respecto a la determinación del régimen de prescripción aplicable, que menoscaba el principio de precisión de la ley aplicable . De ser así, el juez nacional no está obligado a dejar sin aplicación las disposiciones controvertidas del Código Penal ${ }^{32}$.

Por otra parte, los requisitos de previsibilidad, de precisión y de irretroactividad inherentes al principio de legalidad suponen un obstáculo a que, en los procedimientos que afectan a personas acusadas de infracciones en materia del IVA antes de que se pronunciase la sentencia caso Taricco, el juez nacional no aplique las disposiciones controvertidas del Código Penal ${ }^{33}$. En esa línea, el Tribunal de la Unión ya señaló, en la sentencia del caso Taricco, que, caso de inaplicación de las disposiciones sobre prescripción, se incurría en el riesgo de imponer a esas personas sanciones que, con toda probabilidad, habrían evitado si se hubieran aplicado las disposiciones. Así, esas personas podrían quedar sujetas retroactivamente a condiciones de exigencia de responsabilidad penal más severas que las vigentes en el momento de la comisión de la infracción.

Si el juez nacional considera que la obligación de no aplicar las disposiciones del Código Penal controvertidas vulnera el principio de legalidad de los delitos y las penas, no debería cumplir dicha obligación y ello aunque su respeto permitiera subsanar una situación nacional opuesta al Derecho de la Unión ${ }^{34}$ (véase, por analogía, la sentencia

32 El Tribunal de la Unión entra en una argumentación circular, que desemboca en que el juez nacional ha de hacer un juicio de valor sobre el principio de precisión de ley, lo que en sí mismo desvirtúa el sentido del principio de precisión de la ley penal.

33 En suma, el juego del principio de legalidad penal, en este caso, en los procesos penales pendientes, enerva o impide la primacía de la norma europea traída a colación.

34 En este pasaje de la sentencia (apartado $n^{\circ}$ 61), la enunciación de la presencia de una situación nacional opuesta al Derecho de la Unión y la llamada a no cumplir con la obligación de dar primacía al Derecho de la Unión suponen, por parte del Tribunal de Luxemburgo, prejuzgar, injustificadamente, la actuación del juez nacional, que en las condiciones argumentadas (apartado n 59 ) «no está obligado» a dejar de aplicar la norma interna sobre prescripción. 
de 10 de julio de 2014, caso Impresa Pizzarotti, asunto C-213/13, apartados 58 y 59). Corresponderá por tanto al legislador nacional adoptar las medidas necesarias para evitar la impunidad de las conductas, como se ha señalado en la presente sentencia.

\section{Competencia compartida}

El elemento más novedoso que permite al Tribunal de la Unión en el caso M.A.S. y M.B. profundizar en su reflexión es la conciencia de que la primacía presupone la competencia ${ }^{35}$. La primacía del Derecho de la Unión no permite invadir los ordenamientos estatales prescindiendo de las competencias de los Estados de la Unión.

La objeción competencial fue planteada por la Corte di Cassazione, según la cual, el artículo 325 de TFUE, interpretado en el sentido de la sentencia del caso Taricco, acabaría por atribuir a la Unión una competencia directa en materia penal, más allá de los límites establecidos en el Derecho originario de la Unión ( «travalica i confini delle attribuzioni riconosciute dal Trattato»), siendo que el artículo 325 de TFUE no es una norma penal sino mas bien una norma sobre la producción normativa ${ }^{36}$.

La conclusión alcanzada por el Tribunal de la Unión en su reflexión sobre este punto es que «Procede añadir que el ámbito de la protección de los intereses financieros de la Unión mediante la imposición de sanciones penales constituye una competencia compartida ${ }^{37}$ entre la Unión y los Estados miembros, en el sentido del artículo 4 TFUE, apartado $2 »^{38}$.

En el presente caso, en el momento de la comisión de los hechos controvertidos en el procedimiento principal, el régimen de prescripción aplicable a las infracciones penales relativas al IVA no había sido objeto de armonización por el legislador de la Unión, que únicamente se produjo después, de forma parcial, mediante la adopción

35 Como ha dicho CARTABIA, M., «Nessun dubbio che il diritto derivato possa godere della qualità della supremazia solo se e nella misura in cui rispetti la delimitazione di competenze tracciata dal Trattato costituzionale europeo. Condizione di validità della legislazione derivata dell'Unione europea è che essa possa esibire una specifica base giuridica nel testo del Trattato, cosicché il problema della sua prevalenza sul diritto nazionale non si pone nemmeno se a priori si rinviene un vizio di incompetenza. [...] Il primato del diritto europeo derivato opera solo all'interno del principio di attribuzione di competenze» (citado por VECCHIO, F. (2002), «Primacía del Derecho europeo y contralímites como técnicas para la relación entre ordenamientos», R.E.D.C.E. 17 ).

36 Tomado de ROMBOLI, S. (2017), «Los contra-límites en serio» y el caso Taricco: el largo recorrido de la teoría hasta la respuesta contundente pero abierta al diálogo de la Corte constitucional», R.E.D.C.E. 28.

37 Las «competencias compartidas» de la Unión son competencias «por relevos», que se caracterizan positivamente por tres notas: $1^{\mathrm{a}}$ «los Estados miembros ejercerán su competencia en la medida en que la Unión no hayan ejercido la suya» $2^{a}$ la adopción de actos por la Unión no excluye la adopción de actos por los Estados en la parte del ámbito competencial no cubierto por el acto de la Unión $3^{a}$ el acto adoptado por la Unión puede contener una habilitación específica a favor de la actuación de los Estados de la Unión.

38 Apartado $^{\circ} 43$ y ss de la sentencia del TJUE de 5 de diciembre de 2017, caso M.A.S. y M.B., asunto C-42/17. 
de la Directiva 2017/1371, del Parlamento Europeo y del Consejo, de 5 de julio de 2017, sobre la lucha contra el fraude que afecta a los intereses financieros de la Unión a través del Derecho penal ${ }^{39}$.

En aquel escenario, por tanto, Italia tenía libertad para prever, en su ordenamiento jurídico, que ese régimen estuviese comprendido, al igual que las normas relativas a la definición de las infracciones y la determinación de las penas, en el Derecho penal material y quedara sometido, como estas últimas normas, al principio de legalidad de los delitos y las penas.

Por su parte, los órganos jurisdiccionales nacionales competentes, cuando, en el curso de procedimientos penales abiertos, decidan dejar sin aplicación las disposiciones del Código Penal controvertidas, habrán de velar por que se respeten los derechos fundamentales de las personas acusadas de haber cometido una infracción penal (en este sentido, la sentencia caso Taricco, apartado 53).

«Los tribunales y las autoridades nacionales están facultados para aplicar estándares nacionales de protección de los derechos fundamentales, siempre que esa aplicación no afecte al nivel de protección previsto por la Carta, según su interpretación por el Tribunal de Justicia, ni a la primacía, la unidad y la efectividad del Derecho de la Unión ${ }^{40}$ (sentencia de 26 de febrero de 2013, caso Åkerberg Fransson, asunto C-617/10, apartado 29)» ${ }^{41}$.

En concreto, en lo tocante a la imposición de sanciones penales, en los procesos pendientes, corresponde a los órganos jurisdiccionales nacionales competentes garantizar que se respeten los derechos fundamentales de los acusados derivados del principio de legalidad de los delitos y las penas.

39 DO 2017, L 198, p. 29.

40 La fórmula proviene de la sentencia del TJUE de 26 de febrero de 2013, caso Melloni, asunto C- 399/11, cuestión prejudicial elevada por el Tribunal constitucional español, en relación con una orden de detención dictada por el Tribunal de Ferrara, en su apartado n 60. Puede verse DUBOUT, E. (2013), «Le niveau de protection des droits fondamentaux dans l'Union européenne: unitarisme constitutif versus pluralismo constitucionnel. Reflexions autour de l'arrêt Melloni», Cabiers de Droit Européenn 2, pp. 293-317. Por razón del principio de mutua confianza o mutuo reconocimiento entre Estados de la Unión, el Tribunal de la Unión ha clarificado que «cuando aplican el Derecho de la Unión, los Estados miembros pueden estar obligados, en virtud de ese mismo Derecho, a presumir que los demás Estados miembros respetan los derechos fundamentales, de forma que les está vedado no sólo exigir a otro Estado miembro un nivel de protección nacional de los derechos fundamentales superior al garantizado por el Derecho de la Unión, sino incluso verificar, salvo en supuestos excepcionales, si ese otro Estado miembro ha respetado efectivamente, en un caso concreto, los derechos fundamentales garantizados por la Unión» (Dictamen 2/13 del TJUE, relativo a proyecto de Acuerdo de Adhesión de la Unión al CEDH, apartado $\mathrm{n}^{\circ}$ 192).

41 SARMIENTO, D. (2013) entiende que se trata de una referencia a supuestos en que, bajo cobertura de la protección de un derecho fundamental, se esconde la intención de un Estado miembro de eludir disposiciones relevantes de Derecho de la Unión ( Who`s Afraid of the Charter? The european Court of Justice, National Courts and the New framework of Fundamental Rights Protection in Europe», Common Markert Law Review 50, pp. 1267 -1304). Ahora bien, en el presente caso, se subraya que la ausencia de medidas de armonización en relación con la competencia compartida abre la puerta al juego del estándar nacional de protección del derecho fundamental implicado. 
Según el tribunal remitente, esos derechos no serían respetados en caso de inaplicación de las disposiciones controvertidas del Código Penal, en el marco de los procesos pendientes ante él, dado que, por una parte, las personas afectadas no podían prever razonablemente, antes de que se pronunciase la sentencia caso Taricco , que el artículo 325 TFUE obligaría al juez nacional, en las circunstancias establecidas en dicha sentencia, a dejar sin aplicación las mencionadas disposiciones.

Por otra parte, según ese mismo Tribunal, sin rebasar los límites que el principio de legalidad de los delitos y las penas impone a su facultad de apreciación, el juez penal no puede definir el contenido concreto de las circunstancias en las que debería dejar sin aplicación esas disposiciones, a saber, en el supuesto de que las mismas impidiesen la imposición de sanciones efectivas y disuasorias en un número considerable de casos de fraude grave.

El Tribunal de la Unión pondrá en relación ambos argumentos de la Corte costituzionale remitente con el principio de precisión de la ley penal aplicable, en lo tocante al régimen de prescripción penal, lo que le llevará a poner entre paréntesis en el caso la primacía del Derecho de la Unión.

En suma, el artículo 325 TFUE, debe interpretarse en el sentido de que, en el marco de un proceso penal sobre infracciones relativas al IVA, obliga al juez nacional a no aplicar reglas internas en materia de prescripción comprendidas en el Derecho material nacional que impiden la imposición de sanciones penales efectivas y disuasorias en un número considerable de casos de fraude grave que afecten a los intereses financieros de la Unión o que establecen, en el caso de fraudes que afecten a dichos intereses, plazos de prescripción más cortos que en el caso de fraudes que afecten a los intereses financieros del Estado, y ello a menos que la inaplicación implique una violación del principio de legalidad de los delitos y las penas, debido a la falta de precisión de la ley aplicable o debido a la aplicación retroactiva de una legislación que impone condiciones de exigencia de responsabilidad penal más severas que las vigentes en el momento de la comisión de la infracción.

\section{REFLEXIONES CONCLUSIVAS}

Habiendo abordado la sentencia del Tribunal de la Unión caso Taricco el problema de la pronta prescripción de los delitos en materia de IVA en el Estado italiano, en perjuicio de los intereses financieros de la Unión, la puesta en práctica de la doctrina Taricco en los procesos penales pendientes, suscitó el interrogante, abordado en el caso M.A.S. y M.B., sentencia del TJUE de 5 de diciembre de 2017, de su puesta en relación con las garantías constitucionales en materia penal.

La profundización de su reflexión por el Tribunal de la Unión le lleva a concluir que las nuevas condiciones de prescripción derivadas de la doctrina Taricco no pueden ser aplicadas retroactivamente a infracciones cometidas con anterioridad a la sentencia prejudicial y que las nuevas condiciones de prescripción derivadas de la doctrina 
Taricco no pueden menoscabar el principio de precisión de la ley penal aplicable originando una incertidumbre sobre la regulación de la prescripción relativa a las infracciones cometidas.

Esta argumentación del Tribunal de la Unión en el caso M.A.S. y M.B., implica dar entrada a la peculiaridad del Derecho italiano, en que las reglas de prescripción se consideran integradas en la prohibición de retroactividad en materia penal y en el principio de precisión de la ley penal aplicable, que son garantías penales sustantivas que gozan de protección a nivel constitucional.

¿Qué escenarios son aquellos en que el Tribunal de la Unión puede presentarse como garante de los derechos fundamentales recogidos en la Constitución de un Estado de la Unión? De la sentencia del caso M.A.S. y M.B., se desprende que lo son aquellos ámbitos competenciales en que la competencia está compartida entre la Unión y los Estados y en que la normativa reguladora no ha sido objeto de armonización por el legislador de la Unión, que son los escenarios en que el Legislador nacional goza de libertad de configuración, en el contexto de los derechos fundamentales de su Constitución política, conforme a los estándares nacionales de protección de esos derechos fundamentales.

Este es el punto de llegada del camino que inició el Tribunal de Cuneo, con su cuestión prejudicial, prosiguieron el Tribunal de apelación de Milán y la Corte di casazione, con sus cuestiones de constitucionalidad y finalizó la Corte costituzionale pidiendo al Tribunal de la Unión una profundización de su doctrina inicial en consideración a los principios constitucionales en materia penal vigentes en el Estado italiano, en su relación con el impuesto sobre el valor añadido.

A continuación, la Corte costituzionale resolverá las dos cuestiones de constitucionalidad concluyendo que: $1^{\circ}$. «L'autorità competente a svolgere il controllo sollecitato dalla Corte di giustizia è la Corte costituzionale, cui spetta in via esclusiva il compito di accertare se il diritto dell'Unione è in contrasto con i principi supremi dell'ordine costituzionale e in particolare con i diritti inalienabili della persona». $2^{\circ}$. «Indipendentemente dalla collocazione dei fatti, prima o dopo l'8 settembre 2015 [data di pubblicazione della sentenza], il giudice comune non può applicare loro la «regola Taricco», perché essa è in contrasto con il principio di determinatezza in materia penale, consacrato dall'art. 25 , secondo comma, Cost.» ${ }^{42}$.

Epílogo: en el posterior caso M. Scialdone, el Tribunal de la Unión acotará que si bien las sanciones que los Estados regulan para luchar contra las infracciones en materia de IVA pertenecen al ámbito de su autonomía procesal e institucional, dicha autonomía está limitada, «además de por el principio de proporcionalidad, por una parte, por el principio de equivalencia, que implica que las sanciones sean análogas a las aplicables a las infracciones del Derecho nacional de naturaleza e importancia similares y que vulneren intereses financieros nacionales, $y$, por otra parte, por el

42 Sentencia ${ }^{\circ} 115$ de 10 de abril de 2018 de la Corte costituzionale. 
principio de efectividad, que impone la exigencia de que dichas sanciones sean de carácter efectivo y disuasorio» ${ }^{43}$.

\section{BIBLIOGRAFIA}

Biglino Campos, P. (2007), «La primacía del Derecho comunitario: la perspectiva española», Revista General de Derecho constitucional, 3, pp. 2-25.

DE Amicis , G. (2018), «Le soglie di punibilità previste dalla legislazione in materia di reati tributari sono conformi alla normativa europea», Cassazione penale 9, pp. 3030-3036.

De Miguel Canuto, E. (2012), «Metodología de la definición y en la protección de los derechos fundamentales de la Unión europea», Tribuna Fiscal, 255, pp. 16-27.

Dubout, E. (2013), «Le niveau de protection des droits fondamentaux dans l'Union européenne: unitarisme constitutif versus pluralismo constitucionnel.Reflexions autour de l'arrêt Melloni», Cabiers de Droit Européenn, 2, pp. 293-317.

FacchinetTi, A. (2018), «La protección de los derechos humanos en la Unión Europea mediante el diálogo judicial: comentario a la sentencia del TJUE en el asunto Taricco II», Revista General de Derecho Europeo, 45, pp. 252-275.

FAGGiAni, V. (2018), «El diálogo jurisdiccional tras la sentencia del TJUE M.A.S. y M.B.: entre estándar europeo de protección y tendencias centrípetas», Revista de Derecho Comunitario Europeo, 60, pp. 639-676.

FeILHES, L. (2018), «TVA, Italie et sanction pénale: le cocktail dangereux à nouveau désamorcé par la Cour de justice», Revue des affaires europeennes, 2, pp. 353-363.

Garcia Vitoria, I. (2018), «La participación de los Tribunales constitucionales en el Sistema europeo de Derechos Fundamentales (a propósito del diálogo entre la Corte Constitucional italiana y el Tribunal de Justicia en el Asunto Taricco)», Revista española de derecho europeo, 67, pp. 139-164.

Groppi, T. (2006), «La primauté del Derecho europeo sobre el Derecho constitucional nacional: un punto de vista comparado», Revista de Derecho Costitucional Europeo, 5 , pp. 225-244.

GuAstaferro, B. (2018), «Derubricare i conflitti costituzionali per risolverli: sezionando il caso «Taricco», Quaderni costituzionali, 2, pp. 441-461.

LANOTTE, M. (2019), «L'impunità degli autori delle frodi carosello e le contromisure per la tutela degli interessi finanziari europei», Diritto penale contemporaneo 6, pp. 189 a 206.

43 Apartado $\mathrm{n}^{\circ} 29$ de sentencia del TJUE de 2 de mayo de 2018 , caso M. Scialdone, asunto C-574/15, (Italia). Puede verse DE AMICIS, G., «Le soglie di punibilità previste dalla legislazione in materia di reati tributari sono conformi alla normativa europea», Cassazione penale 9, 2018, pp. 30303036; FEILHES, L., «TVA, Italie et sanction pénale : le cocktail dangereux à nouveau désamorcé par la Cour de justice», Revue des affaires europeennes 2, 2018, pp. 353-363. 
Lupo, E. (2016), «La primauté del diritto dell’UE e l'ordinamento penale nazionale», Diritto penale contemporáneo 1 , pp. 217-227.

Matia Portilla, F.J. (2016), «Primacía del Derecho de la Unión y derechos constitucionales: en defensa del Tribunal constitucional», Revista Española de Derecho Constitucional 106, pp. 479-522.

Mori, P. (2017), «La Corte constituzionale chiede alla Corte di giustizia di rivedere la sentenza Taricco: difesa dei controlimiti o rifiuto delle limitazioni di sovranità in materia penale?», Rivista di diritto internazionale 2, pp. 407-446.

Nettesheim, M. (2003), «El significado constitucional de la primacía del Derecho Comunitario / de la Unión», Revista española de Derecho europeo, 6, pp. 279-289.

Perlo, N. (2017), «L'affaire Taricco: la voie italienne pour préserver la collaboration des juges dans l'Union européenne», Revue trimestrielle de droit europeen, 4, pp. 739-768.

Puissochet, J.-P., de Mendizabal Allende, R., y Campos Sanchez-Bordona, M. (2006), «La primacía del Derecho comunitario», Estudios de Derecho judicial, 95, pp. 19-69.

Pulitano, D.,(2016), «La posta in gioco nelle decisione della Corte costituzionale sulla sentenza Taricco», Diritto penale contemporáneo, 1, pp. 228-237.

Rodriguez Bereijo Leon, M. (2016), «La Sentencia del TJUE en el caso «Ivo Taricco y otros» y la aplicación extensiva del principio de efectividad en relación con la persecución del fraude en el IVA», Revista española de derecho europeo, 58, pp. 171-198.

Romboli, S., (2017), «Los contra-límites en serio» y el caso Taricco: el largo recorrido de la teoría hasta la respuesta contundente pero abierta al diálogo de la Corte constitucional», Revista de Derecho Constitucional Europeo, 28.

Ruiz-Jarabo y Colomer, D. (1986), «La primacía del Derecho comunitario europeo», Noticias de la Unión europea, 12, pp. 97-101.

SANTAmaria Dacal, A. I. (2009), «Una reflexión más sobre la primacía del Derecho comunitario con ocasión de la sentencia Michaniki y a la luz del Tratado de Lisboa», Revista española de Derecho europeo, 30 , pp. 223-241.

SANZ Diaz-Palacios, J. A. (2016), «La lucha contra el «fraude carrusel» del Impuesto al Valor añadido en Italia: Comentario a una Sentencia del Tribunal de Justicia de la Unión Europea», Análisis Tributario, 341, pp. 26-31.

Sarmiento, D. (2013), «Who's Afraid of the Charter? The european Court of Justice, National Courts and the New framework of Fundamental Rights Protection in Europe», Common Markert Law Review, 50, pp. 1267 -1304.

Tenorio Sánchez, P. J. (2013), «Diálogo entre tribunales y protección de los derechos fundamentales en el ámbito europeo», Revista General de Derecho Europeo, 31.

Vecchio, F. (2002), «Primacía del Derecho europeo y contra-límites como técnicas para la relación entre ordenamientos», Revista de Derecho Constitucional Europeo 17, pp. 67-102. 
Vigano, F. (2017), «Legalita ' nazionale ' e legalita ' europea' in materia penale : I difficili equilibrismi della corte di giustizia nella sentenza M.A.S. («Taricco II»), Rivista italiana di diritto e procedura penale, 4, pp. 1281-1314.

Vitale, G. (2018), «L'attesa sentenza «Taricco bis»: brevi riflessioni», European papers: a journal on law and integration, 1, pp. 445-458.

Title:

The CJEU as guarantor of fundamental rights in the States: Taricco jurisprudence

\title{
Summary:
}

I. Consecutive processes. II. Ivo Taricco case: principle of primacy. 1. Conformity with Union Law 2. Consequences of the incompatibility with the Law of the Union 3. Fundamental rights. III. M.A.S. and M.B. case: constitutional rights. 1. Starting points. 2. Jurisprudence. 3. Principle of criminal legality. 4. Shared competence. IV. Conclusive reflections. Bibliography.

\section{Resumen:}

¿Qué escenario es aquel en que el Tribunal de Justicia de la Unión Europea puede presentarse como garante de los derechos fundamentales recogidos en la Constitución de un Estado de la Unión? La reflexión del Tribunal de la Unión en el caso M.A.S. y M.B., en cuestión prejudicial elevada por la Corte costituzionale italiana, continuación del anterior caso Taricco, dio ocasión al Tribunal de la Unión a identificar ese escenario, en un caso relativo a la prescripción penal en materia de impuesto sobre el valor añadido.

\begin{abstract}
:
In which scenario can the Court of Justice of the European Union appear as guarantor of the fundamental rights contained in the Constitution of a State of the Union? The analysis of the CJEU in the M.A.S. and M.B., in a preliminary ruling raised by the Italian Corte costituzionale, following the previous Taricco case, gives the CJEU the opportunity to draw this scenario, in a matter related to the criminal prescription in relation to value-added tax.
\end{abstract}




\section{Palabras clave:}

Derechos constitucionales; IVA; prescripción; primacía del Derecho de la UE.

Key words:

Fundamental rights; primacy of EU law; time limits; VAT. 
